\title{
Прогнозирование банкротства компаний нефтегазового сектора с использованием нейросетей
}

\author{
Макеева Е.Ю. ${ }^{4}$, Бакурова А.O. ${ }^{5}$
}

В условиях современной нестабильной экономической ситуаџии корректное оценивание финансового положения компании и прогнозирование потенциала ее дальнейшей операционной деятельности представляется весьма актуальным как для самой компании (для корректного планирования и построения долгосрочных стратегий развития), так и для других участников рынка (для корректного определения стоимости компании в случае проведения сделки слияния и поглощения). В рамках текущей работь рассматривалась проблема оценки вероятности банкротства компаний нефтегазового сектора. Нефтегазовый сектор считается наиболее стабильным и консервативным - за счет специффики производимых продуктов и специфики организащии бизнеса. В то же время существует большое число небольших (в масштабах трансконтинентальных компаний) нефтегазовых предприятий, деятельность которых не «страхуется» государством или более крупными, материнскими, компаниями, а потому им значительно сложнее удерживать финансовое равновесие. Поэтому результатом сильных экономических потрясений является банкротство подобных компаний.

JEL: G12, G13, G32, G33

Ключевые слова: банкротство, нефтегазовый сектор, нейросети

\section{Обзор литературы и постановка проблемы}

Многие эксперты продолжают спорить относительно того, вышла ли мировая экономика из кризиса 2009 года или нет, но неоспоримым является тот факт, что весь мир все еще переживает тяжелые его последствия, например волну новых кризисов, прокатившуюся по отдельным странам Евросоюза в 2010-2011 годах.

Знаковые банкротства ${ }^{6}$ последних лет еще раз подтверждают важность прогнозирования финансовой устойчивости компаний. Сегодня как никогда требуется разработка систем раннего реагирования, которые смогли бы уберечь компании от банкротства и позволили бы инвесторами более эффективно тестировать компании на предмет устойчивости.

Исследование вопросов банкротства в данной статье проводится на примере европейских компаний нефтегазового сектора. Традиционно такие предприятия не ассоциируются с понятием банкротства, однако статистика показывает обратное. Наибольшее число банкротств в кризисный и посткризисный период пришлось именно на нефтегазовый сектор. В то же время необычайную активность показал рынок слияний и поглощений. В этот период значительно увеличился объем сделок, при этом рост числа сделок сопровождался падением средней цены сделки. Таким образом, подтверждается предположение о том, что банкротство одних компаний может служить благоприятной платформой для расширения других предприятий.

\footnotetext{
${ }^{4}$ Канд. эконом. наук, доцент кафедры экономики и финансов фирмы НИУ ВШЭ.

${ }^{5}$ Выпускница магистерской программы «Корпоративные финансы» НИУ ВШЭ.

${ }^{6}$ Банкротство - признанная уполномоченным государственным органом неспособность должника (гражданина либо организации) удовлетворить в полном объеме требования кредиторов и (или) исполнить обязанность по уплате обязательных государственных платежей.
} 
Рассматривая историю развития методики прогнозирования банкротства, необходимо отметить, что анализ финансовых показателей начался с разработки одного-единственного коэффициента - коэффициента текущей ликвидности (current ratio), который используется для оценки платежеспособности. Позднее финансовый анализ, основанный на расчете и сопоставлении различных показателей, стал очень популярным среди управленцев, кредиторов, инвесторов и рейтинговых агентств.

Одним из первых обратил свое внимание на финансовые коэффициенты как на инструмент прогнозирования банкротства компаний Уильям Бивер. В своей работе (Biver, 1966) он дал определения таким понятиям, как финансовый коэффициент, предсказательная сила финансового коэффициента; попытался эмпирически проверить полезность этих коэффициентов, а также влияние тех или иных факторов на вероятность банкротства компании.

Так, были выделены четыре принципа: (1) чем выше объем ликвидных активов, тем ниже вероятность банкротства; (2) чем выше чистый операционный денежный поток, тем ниже вероятность банкротства; (3) чем выше размер долга, тем ниже вероятность банкротства; (4) чем выше капитальные вложения, тем выше вероятность банкротства. В ходе исследования Бивер пришел к тому, что разные коэффициенты имеют разную предсказательную силу; особенно высокой селективной силой отличается отношение денежных потоков к общему объему долговых обязательств. Его одномерная теория анализа финансовых показателей стала хорошей базой для формирования аналогичной многомерной модели.

В дальнейшем Эдвард Дикин повторил процедуру, продолженную Бивером, а также попытался найти линейную комбинацию 14 показателей, использовавшихся в работе Бивера, которая смогла бы наилучшим образом предсказывать банкротство за каждые пять лет до его наступления. Дикин использовал для анализа 32 компании, обанкротившиеся в период с 1964 по 1970 год. К категории обанкротившихся он относил компании, показавшие некредитоспособность, финансовую несостоятельно, а также ликвидированные в пользу кредитора, в то время как Бивер рассматривал компании, не выполнившие кредитных обязательств и/или не осуществивших выплаты по привилегированным акциям.

Большим прорывом в области оценки вероятности банкротства компании стала опубликованная в 1968 году работа Альтмана, в которой он предлагал одномерную модель дискриминантного анализа финансового состояния предприятия (Altman, 1968).

В ходе своего исследования Альтман получил следующее уравнение:

$$
Z=0,012 X_{1}+0,014 X_{2}+0,0033 X_{3}+0,006 X_{4}+0,99 X_{5}
$$

где:

$X_{1}$ - рабочий капитал / суммарные активы - показатель ликвидности;

$X_{2}$ - нераспределенная прибыль / суммарные активы - показатель рентабельности;

$X_{3}$ - EВIT / суммарные активы - показатель финансовой состоятельности;

$X_{4}$ - рыночная капитализация / балансовая стоимость долга - показатель финансового рычага;

$X_{5}$ - продажи / суммарные активы - показатель активности.

С вероятностью 83\% модель прогнозирует банкротство за два года до его наступления, и с вероятностью 95\% - за год. Отрезок значений $Z[1,81 ; 2,9]$ называют зоной неопределенности (серой зоной) из-за высокой вероятности принятия ошибочного решения. Если Z-фактор ниже 1,81, прогнозируется скорое банкротство. Если же Z-фактор выше 2,99 в ближайшие два года банкротство компании не грозит.

Нужно, однако, отметить, что такие коэффициенты получаются, если переменные $X_{1}$ $X_{4}$ берутся в абсолютном процентном выражении (то есть $10 \%$, а не 0,1 ), в то время как пятая переменная берется в долевом выражении. Если же все переменные взять в долевом выражении, то уравнение примет следующий вид:

$$
Z=1,2 X_{1}+1,4 X_{2}+3,3 X_{3}+0,6 X_{4}+0,99 X_{5} .
$$


Далее, в 2000 году, Альтман протестировал модель на новых данных, подтвердив ее состоятельность и эффективность на уровне 82-94\%. Также в новой работе автор преобразовал четвертую переменную, заменив рыночную стоимость собственного капитала на балансовую ${ }^{7}$, и получил новые коэффициенты и критерии классификации:

$$
Z=0,71 X_{1}+0,84 X_{2}+3,1 X_{3}+0,42 X_{4}+0,99 X_{5} \text {. }
$$

Таким образом, замена одной переменной привела к сокращению значений всех коэффициентов.

Позднее, в 1975 году, Роберт Либби попытался объединить в своей работе (Libbi, 1975) разные подходы в оценке вероятности банкротства, рассматриваемые ранее отдельно. Либби хотел выяснить, помогают ли финансовые показатели компании прогнозировать кредиторам вероятность ее банкротства. Полезность той или иной информации измерялась умением прогнозировать кредиторов, которым предоставлялся доступ к ограниченному набору показателей.

В 1987 году Гуди (Goudie, 1987) тестировал модифицированную модель Альтмана на данных производственных и распределительных компаний Соединенного Королевства за период с 1960 по 1974 год. Исследование также было проведено с использованием дискриминантного анализа. Главное же отличие модели Гуди от модели Альтмана - набор используемых переменных. Однако процедура отбора переменных была позаимствована им у Бивера.

Таким образом, в 60-е, 70-е годы XX века основным подходом для разработки моделей прогнозирования банкротства являлся многомерный дискриминантный анализ. Позднее, в начале 80-х, стали применяться более продвинутые модели: такие как логит-анализ (Ohlson, 1980) и пробит-анализ (Zmijevsky, 1984).

Одним из современных инструментов прогнозирования банкротства являются нейронные сети. Последние исследования в области искусственных нейронных сетей (ANN) показали, что они выступают мощным инструментом в распознавании образов и классификаций благодаря своим нелинейным непараметрическим свойствам адаптивного обучения.

Многие исследователи, занимавшиеся проблемой прогнозирования банкротства, заключают, что нейронные сети дают значительно более высокую точность прогноза, чем классические статистические подходы.

В своей работе Дж. Джанг, М. Ху, Е. Патуво, Д. Индро (Zhang, Hu, Patuwo, etc., 1999) показывают, что выходные сигналы нейронной сети - это оценки апостериорных баесовских вероятностей, которые играют важную роль в традиционной статистической классификации и в задачах распознавания образов в частности.

При использовании нейронных сетей все доступные данные случайным образом делятся на обучающую (in-sample) и тестирующую (out-of-sample) выборки. Обучающая выборка необходима для построения модели нейронной сети, а тестирующая - для оценки качества построенной модели. Однако случайность в разделении массива данных на две части может вызывать искажения результатов, особенно если используются небольшие выборки. Для более точного описания продуктивности нейронных сетей используют схемы кросс-валидации (cross validation - перекрестная проверка). Преимущество кросс-валидации заключается в том, что все наблюдения в имеющейся выборке используются для тестирования и большая их часть используется также для обучения модели. Анализ методом кросс-валидации дает ценную информацию о надежности нейронной сети с точки зрения выборочной дисперсии.

Нейронная сеть, как правило, состоит из нескольких слоев, каждый из которых содержит множество вычисляющих элементов, узлов. Каждый узел получает входной сигнал

\footnotetext{
${ }^{7}$ Балансовая стоимость собственного капитала - величина собственного капитала в соответствии с финансовой отчетностью и бухгалтерской документацией, взятая без внесения каких-либо поправок. Балансовая стоимость включает в себя уставной капитал, эмиссионный доход (разницу между выручкой от реализации акций и их номинальной стоимостью), резервы и нераспределенную прибыль.
} 
от другого узла или внешних источников. После локальной обработки сигнала он передает трансформированный сигнал другим узлам или формирует результирующий сигнал. Главной характеристикой сети является ее архитектура: количество слоев, количество узлов в каждом слое и тип связей между узлами.

Первый слой (input layer), где собирается внешняя информация, называется входным. Последний слой (output layer), где сеть выдает результаты, - выходным. Между ними находятся скрытые слои (hidden layer), которые чрезвычайно важны для определения сложных взаимосвязей внутри данных. Все узлы в прилегающих слоях соединены с первым и последним слоями ациклическими дугами.

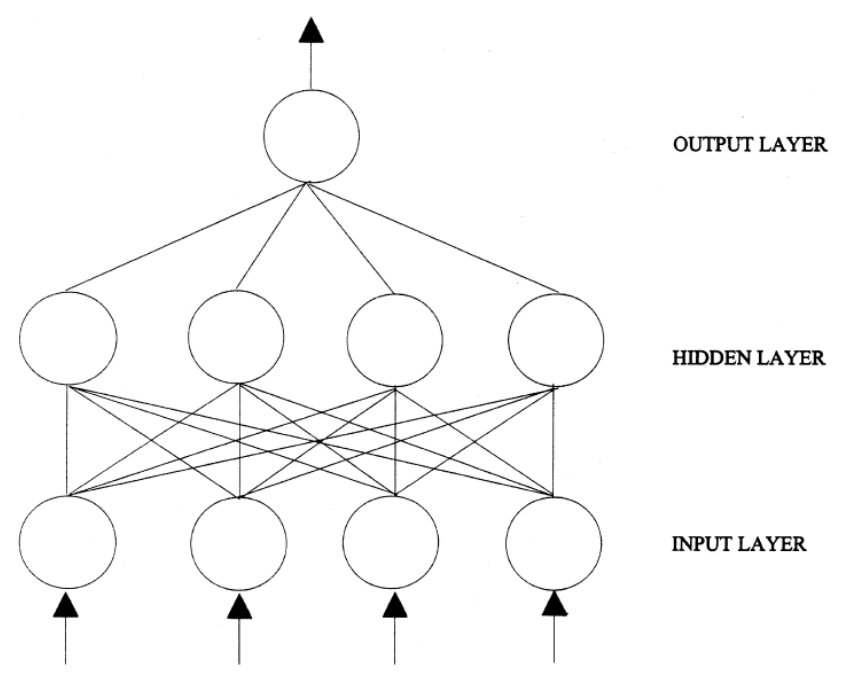

Рисунок 1. Многослойный персептрон с одним скрытым слоем и одним результирующим узлом

На рисунке 1 изображен многослойный персептрон с одним скрытым слоем и одним результирующим узлом.

Так же, как и в любой статистической модели, параметры нейронной сети (веса) должны быть оценены до того, как она будет использована для прогнозирования. Процесс определения весов называется обучением. Процесс обучения - решающий этап при использовании нейронных сетей. При обучении выходной сигнал для каждой входящей выборки заранее известен и задается извне. Взвешенные входные сигналы аккумулируются в скрытых узлах, в которых они преобразуются и становятся входными сигналами для конечного узла. В конечном узле суммируются все взвешенные входные элементы, образуя выходной сигнал. Этот сигнал сравнивается с желаемой величиной. Цель обучения сети минимизировать расхождения между результатом, полученным из ИНС, и известной целевой величиной.

В статье Джанг (Zhang, 1999) рассматривается вопрос о том, дают ли нейросети значимые преимущества при оценке вероятности банкротства. В своем исследований он рассматривает шесть финансовых показателей (пять таких же, как и в модели Альтмана, а шестой - коэффициент текущей ликвидности). Для анализа были взяты американские публичные компании, торгующиеся на Нью-Йоркской, американской биржах и бирже NASDAQ. По итогам исследования, Джанг заключил, что нейронные сети действительно являются более эффективным методом оценки вероятности банкротства именно благодаря тому, что опускаются предпосылки, значимые для традиционных статистических моделей.

Годом ранее исследователи Джо и Хан (Jo и Han, 1998) попытались объединить модели классификации для повышения прогнозной силы модели. В своей работе они предлагают новый структурный подход, состоящий из четырех этапов: обучение, тестирование, подгонка и прогнозирование - и трех типов входных данных: обучаемые, тестовые и обобщенные. При оценке комбинируются несколько подходов: структурная модель, дискриминантный анализ и два механизма искусственного интеллекта (нейронные сети и case-based-прогнозирование). 
Для анализа были взяты корейские компании, обанкротившиеся в период с 1991 по 1993 год (число обанкротившихся и не обанкротившихся компаний равно). При отборе финансовых показателей учитывались два фактора: частота использования данного показателя в предыдущих исследованиях и его популярность среди рейтинговых агентств. Таким образом, была сформирована выборка из 20 объясняющих переменных. В работе показано, что эффективность объединенной модели выше, чем эффективность ее составляющих.

Позже, в 2009 году, С. Хо также опубликовал работу посвященную проблеме интеграции традиционных статистических подходов к оценке вероятности банкротства и инновационных подходов искусственного интеллекта (Cho, 2009). В частности, он предложил объединить дискриминантный анализ, логистическую регрессию, нейронные сети и модель дерева решений. Тестирование данной модели на реальных данных показало, что по отношению к каждому исходному методу она дает значительное улучшение с точки зрения эффективности.

\section{Описание выборки и методики исследования}

В представленном исследовании рассматривались европейские компании нефтегазового сектора, данные по которым были взяты из информационных баз Amadeus, Bloomberg и Capital IQ. Часть компаний обанкротилась в период с 2000 по 2010 год, остальные компании функционируют и по настоящий день. Выборка была разделена на до- и посткризисный периоды для выявления значимых различий в детерминантах банкротства. Далее представлен более детальный анализ собранных данных.

В качестве базовой модели исследования рассматривается модель, включающая группы показателей аналогичные тем, что использовались в более ранних работах: финансовый рычаг, ликвидность, оборачиваемость, рентабельность.

В качестве финансового рычага в текущем исследовании было принято соотношение суммарных обязательств и собственного капитала. При среднем значении 2,18 (1,72 для компаний банкротов и 3,12 - не-банкротов) значения финансового рычага колеблются от 0 (то есть в какой-то период времени у некоторых компаний вообще не было долговых обязательств) до 27,44 (то есть в какой-то период у компаний очень высокий уровень привлечений, вызванный, возможно, высоким уровнем капитальных вложений, которые могут себе позволить именно устойчивые компании). Предпосылки эконометрической модели предполагают нормальность и независимость факторов. Индикаторами нормальности служат показатели асимметрии и эксцесса ${ }^{8}$

Существуют различные пути преобразования данных, среди которых такие методы, как возведение в различные степени и логарифмирование. В случае смещения распределения вправо (когда левый хвост распределения сильно сжат, а правый, наоборот, растянут) полезно применять логарифмическое преобразование. На рисунке 2 прослеживается эффективность данного преобразования. На графиках (рис. 2), представленных ниже, сопоставляются гистограммы распределения наблюдений до и после лог-трансформации.

\footnotetext{
${ }^{8}$ Считается, что данные распределены нормально, если показатель асимметрии близок к нулю (не выходит за пределы -1/2;1/2), а показатель эксцесса приблизительно равен 3.
} 

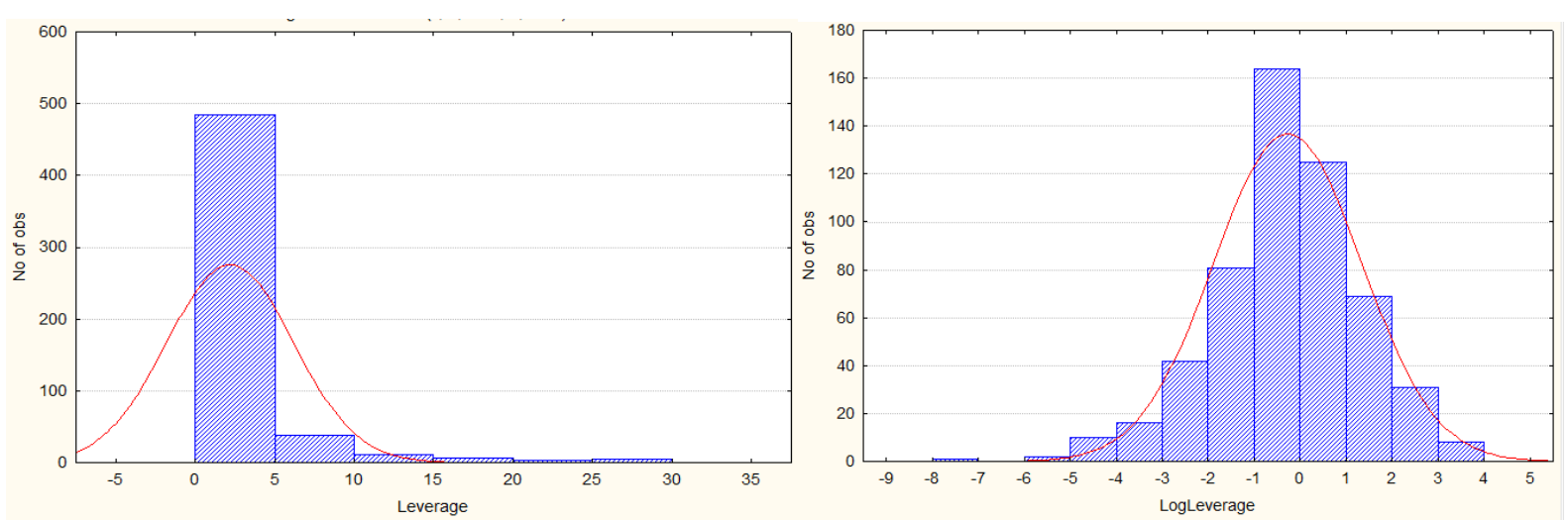

Рисунок 2. Гистограмма распределения значений финансового рычага

Под ликвидностью в данном исследовании мы понимаем соотношение текущих активов и текущих обязательств. Для компаний-банкротов средний уровень ликвидности составляет 1,66, а для здоровых компаний - 3,28. Максимальное значение ликвидности 22,03 - то есть в выборке присутствуют компании, чья политика операционного управления достаточно вялая, либо средства аккумулировались для последующего инвестирования. Вообще, истинные мотивы накопления активов редко освещаются. Так, одна из крупнейших российских компаний - «Сургутнефтегаз» - из года в год накапливает активы без видимой на то причины, никак не комментируя такую политику (рис. 3).
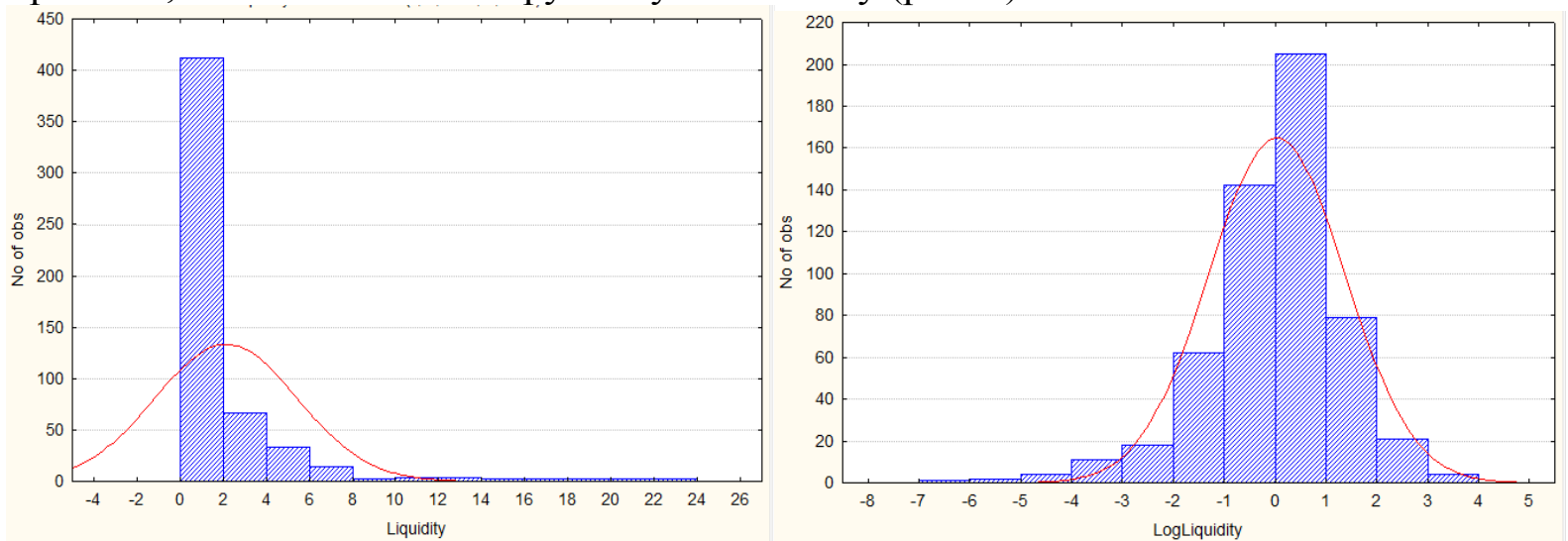

Рисунок 3. Гистограмма распределения ликвидности

Показатель оборачиваемости рассчитан как соотношение рабочего капитала и суммарных активов. Среднее значение по оборачиваемости для финансово устойчивых компаний выше, чем для компаний-банкротов $(0,062$ против 0,009$)$. Показатель оборачиваемости по всей выборке варьируется от $-0,95$ (текущие обязательства компании превышают ее текущие активы) до 0,76. Данные по оборачиваемости активов имеют нормальное распределение. Об этом в первую очередь говорят показатель асимметрии в размере $-0,24$ и эксцесса в размере 3,92 .

В качестве оценки рентабельности в нашем исследовании использовалось отношение чистого дохода и суммарных активов. Среднее значение рентабельности для обанкротившихся компаний составляет $-0,038$ (это говорит о негативной чистой прибыли), а для здоровых компаний - 0,067. В выборке присутствуют как более или менее прибыльные компании, так и убыточные. Распределение данных по рентабельности близко к нормальному виду, что также видно и из статистик (показатель асимметрии равен 1,72, а показатель эксцесса - 12,28), однако присутствует некоторое смещение вправо и превышен показатель эксцесса. При этом любые преобразования этих данных ведут к ухудшению текущего положения. Таким образом, данный показатель не претерпел дополнительной трансформации и был включен в модель в своем исходном виде.

На основе проведенного анализа были сформулированы следующие гипотезы для моделирования вероятности банкротства: 
Гипотеза 1: вероятность банкротства снижается с ростом рентабельности, ликвидности и оборачиваемость компании

Гипотеза 2: вероятность банкротства понижается при сокращении отклонения финансового рычага от его нормального значения

Поскольку основной целью работы являлось выявление основных детерминант финансовой неустойчивости компаний нефтегазового сектора, в качестве зависимой переменной мы рассматриваем бинарную величину, которая принимает значение 1 , если компания обанкротилась, и 0 в противном случае. В качестве независимых переменных мы рассматриваем описанные выше показатели.

Ранее мы рассматривали возможную взаимосвязь финансового рычага и таких показателей, как ликвидность и рентабельность. Оригинальные данные показывают наличие высокой положительной корреляции между финансовым рычагом и ликвидностью $(0,35)$, что совпадает с описанными выше выводами, и слабую отрицательную зависимость между рычагом и рентабельностью (-0,04 - не является значимой), что также подтверждает наши ожидания. Основным способом избавления от внутренней корреляции является трансформация данных (нормализация, логарифмирование, замена исходных данных лагированными). Однако для получения нормально распределенных входных данных показатели ликвидности и финансового рычага уже претерпели логарифмическую трансформацию. Попытка ввести лаговые показатели привела к повышению корреляции с другими показателями. Решением данной проблемы стала замена показателя финансового рычага. Вместо него в модель было включено абсолютное отклонение финансового рычага от целевого значения. В качестве целевых значений были взяты средние по отрасли (рассматривались компании, сопоставимые по размерам суммарных активов) показатели финансового рычага в конкретной стране в конкретный год. Таким образом, корреляция между показателями финансового рычага и ликвидности заметно сократилась (до 0,17$)$.

Поскольку зависимая переменная - бинарная величина, для оценки зависимости использовалась логарифмическая регрессия.

Итоговая модель прогнозирования банкротства для компаний нефтегазового сектора выглядит следующим образом:

(4) Probability $=\left(1+\varepsilon^{-(0,6-5,1 \text { Pr ofitabilit } y+0,96 \text { Turnover }+0,6 \text { LogLiquidi ty-0,3 LogLeverag } e)^{-1}}\right.$.

Предельный эффект $Z=X^{\prime} \beta$ на вероятность банкротства $(f(Z))$ определяется как производная функции вероятности по $Z$ :

$$
f(Z)=\frac{e^{-Z}}{\left(1+e^{-Z}\right)^{2}} .
$$

Чтобы оценить предельный эффект каждой переменной, сначала нужно вычислить значение $Z$ при средних значениях переменных, затем вычислить и умножить на соответствующий коэффициент. Таким образом, единичное увеличение рентабельности сокращает вероятность банкротства в 1,08 раза; единичное увеличение оборачиваемости повышает вероятность банкротства в 0,2 раза; увеличение ликвидности на $1 \%$ ведет к сокращению вероятности банкротства в 0,13 раза; увеличение отклонения финансового рычага на $1 \%$ ведет к увеличению вероятности банкротства в 0,06 раза. Результаты по рентабельности, ликвидности и финансовому рычагу ожидаемы. Стабильная компания характеризуется высокой рентабельностью и ликвидностью и малым отклонением рычага от нормального значения. Результат по оборачиваемости несколько отличается от общепринятых, поскольку он отражает эффективность управления активами. Однако высокий уровень оборачиваемости может сигнализировать о недокапитализации и неспособности приобретать новые активы. Чем крупнее компания, тем ниже вероятность банкротства. Размер компании можно определить через суммарный объем активов. То есть чем ниже суммарный объем активов, тем выше вероятность банкротства. Также чем ниже суммарный объем активов, тем ниже коэффициент оборачиваемости. 
Поскольку при оценке использовалась логистическая регрессия, полученные результаты интерпретируются иначе, чем в простой линейной регрессии. Переменные, коэффициенты при которых имеют отрицательное значение, отрицательно коррелированы с вероятностью банкротства. Наибольшей магнитудой среди всех переменных отличается показатель рентабельности. Этот факт совпадает с выводами других исследователей, в моделях которых рентабельность тоже получала наибольший вес независимо от того, учитывалась в модели отраслевая специфика или нет.

Общая предсказательная сила логит-модели составила 76\%, что является достаточно хорошим показателем. Высока вероятность ошибки первого рода (переоценить угрозу банкротства). Однако возможность возникновения ошибки второго рода (недооценить угрозу банкротства) значительно ниже, что в условиях поставленной задачи является приоритетным (таблица 1).

Таблица 1

Матрица корректности классификации (логистическая регрессия)

\begin{tabular}{|c|c|c|c|c|}
\hline \multirow{2}{*}{} & & \multicolumn{3}{|c|}{ Прогноз (Predicted) } \\
\cline { 2 - 5 } & Не банкроты 0 & Банкроты 1 & $\begin{array}{c}\text { Вероятность прогнозных значений } \\
\text { (Correct predictions), \% }\end{array}$ \\
\hline \multirow{2}{*}{ Наблюдения } & 0 & 74 & 107 & 40,9 \\
\cline { 2 - 5 } & 1 & 23 & 345 & 93,8 \\
\hline
\end{tabular}

Эффективность прогнозирования повышает модель искусственной нейронной сети (многослойный персептрон с одним скрытым слоем), поскольку веса рассчитываются для каждого конкретного случая, образуя в итоге матрицу весов. Ошибка второго рода сокращается до нуля, а общая эффективность прогнозов повышается до 98\% (таблица 2).

Матрица корректности классификации (нейронная сеть)

\begin{tabular}{|c|c|c|c|c|}
\hline \multirow{2}{*}{} & & \multicolumn{3}{|c|}{ Прогноз (Predicted) } \\
\cline { 2 - 5 } & Не банкроты 0 & Банкроты 1 & $\begin{array}{c}\text { Вероятность прогнозных значений } \\
\text { (Correct predictions), \% }\end{array}$ \\
\hline \multirow{2}{*}{ Наблюдения } & 0 & 127 & 7 & 94,8 \\
\cline { 2 - 5 } & 1 & 0 & 266 & 100 \\
\hline
\end{tabular}

Среди оцениваемых параметров нейросеть выделяет показатель рентабельности как самый значимый фактор при оценке вероятности банкротства компаний нефтегазового сектора. Однако значимость остальных факторов лишь немногим ниже (таблица 3).

Таблица 3

Важность показателей модели

\begin{tabular}{|l|c|c|}
\hline \multicolumn{1}{|c|}{ Показатели } & Важность & $\begin{array}{c}\text { Нормализованная важность, } \\
\%\end{array}$ \\
\hline Прибыльность Profitabilityl & 0,296 & 100,0 \\
\hline Оборачиваемость Turnover & 0,262 & 88,4 \\
\hline Логарифм ликвидности LogLiquidity & 0,215 & 72,8 \\
\hline $\begin{array}{l}\text { Логарифм изменения финансового рычага } \\
\text { LogDeltaLeverage }\end{array}$ & 0,227 & 76,6 \\
\hline
\end{tabular}

Хотелось бы, однако, отметить, что нейронные сети - это инструмент, результаты применения которого очень зависят от того, какая выборка применялась. Поскольку 
невозможно использовать всю существующую информацию при анализе того или иного события, возникает высокий риск получения смещенных результатов.

Таким образом, на основе проведенного выше анализа можно заключить, что гипотеза 1 подтверждается в части рентабельности, ликвидности и отклонения рычага, но не подтверждается в части оборачиваемости; а гипотеза 2 подтверждается полностью.

\section{Список литературы}

1. Зинкевич Н.В., Олеванова Е.А. Эмпирическое тестирование теорий структуры капитала: модели, направления, результаты // Корпоративные финансы. 2008. № 1(5). C. 81-102.

2. Altman, E.I. (2009), Financial Ratios, Predicting financial distress of companies: revisiting the Z-score and Zeta Models. URL: http://pages.stern.nyu.edu/ ealtman/PredFnclDistr.pdf.

3. Altman, E.I. (1968), Financial Ratios, Discriminant Analysis, and the Prediction of Corporate Bankruptcy, Journal of Finance, 23(3) (1968) 589-609.

4. Cho, S., Kim, J., Bae, J.K. (2009), An integrative model with subject weight based on neural network learning for bankruptcy prediction, Expert Systems with Applications, 36 (2009) 403-410.

5. Goudie, A.W.(1987), Forecasting Corporate Failure: The Use of Discriminant Analysis within a Disaggregated Model of the Corporate Sector, Journal of the Royal Statistical Society, 1(150) (1987) 69-81.

6. Ohlson, J.A. (1980), Financial ratios and Probabilistic Prediction of Bankruptcy, Journal of Accounting Research, 18(1) (1980) 109-131.

7. Uod, G. (1993), Neural network performance on the bankruptcy classification problem // Computers and Industrial Engineering, 1-4(25) (1993) 377-380.

8. Zhang, G., Hu, M.Y., Patuwo, B.E., Indro, D.C. (1999), Artificial neural networks in bankruptcy prediction: General framework and cross-validation analysis, European Journal of Operational Research, 1(116) (1999) 16-32.

9. Zmijewski, M.E. (1984), Methodological Issues Related to the Estimation of Financial Distress Prediction Models, Journal of Accounting Research, 20 (1984) 59-82. 